\title{
STATIC STRUCTURAL ANALYSIS OF GO-KART CHASSIS
}

\author{
P. N. V. BALA SUBRAMANYAM ${ }^{1}$, B. NAGESWARA RAO ${ }^{2}$,
} O. NAGA SREE HARSHA ${ }^{3} \&$ M. PAVAN SAI KUMAR ${ }^{3}$

${ }^{I}$ Research Scholar, Department of Mechanical Engineering, Koneru Lakshmaiah Educational Foundation,

Vaddeswaram, Guntur, Andhra Pradesh, India

${ }^{2}$ Professor, Department of Mechanical Engineering, Koneru Lakshmaiah Educational Foundation,

Vaddeswaram, Guntur, Andhra Pradesh, India

${ }^{3} U G$ Graduates, Department of Mechanical Engineering, Koneru Lakshmaiah Educational Foundation,

Vaddeswaram, Guntur, Andhra Pradesh, India

\section{ABSTRACT}

The study on rule book prescribed for Go-kart, designing the kart according to the arrangement of all parts is presented in this paper. Through different design events, students can show interest towards designing and analyzing the model obtained. This design of the Go-kart is based on the rules and regulations, set by the event organization, Imperial Society of Innovative Engineers, 2017(This rule book changes every year on considering the safety factor of the driver and innovative ideas). The Designing of the Go-kart is carried out in the SOLID WORKS 13.0 and analyzed in ANSYS 17.1 by considering different types of materials and application of loads.

KEYWORDS: Go-Kart, Chassis, SOLID WORKS 13.0, ANSYS 17.1, Innovation \& Safety Factor

Received: Feb 17, 2019; Accepted: Mar 07, 2019; Published: Mar 29, 2019; Paper Id.: IJMPERDAPR201978

\section{INTRODUCTION}

Go-karts may appear like little autos, yet there are some characterizing attributes that differ them from ATVs or other small auto-motives. Intelligibly, measure is a major factor, yet one noteworthy part of it is total absence of a customary suspension; here the hub is solidly appended to the edge, no differential, and keeping in mind that thing like camber and caster might be customizable.

Typically, a kart has a solitary brake circle on the back and nothing on the front, and the brake pedal is arranged to one side of the kart, with the throttle on the right, constraining the driver to either learn left-footbraking or go plunging off base. A kart ought to have an exceptionally cozy, perfectly sized seat and no belts of any sort, and considering that karts occasionally have move confines or genuine crash structures that are starting to change.

Be that as it may, regardless of conventional security highlights, karting is viewed as an extremely safe type of motorsport. 


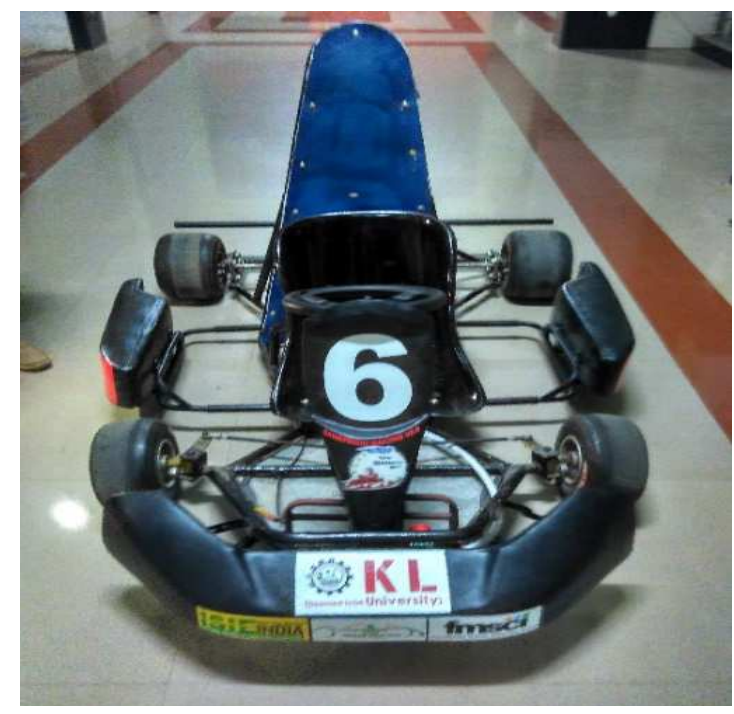

Figure 1: Go-Kart

\section{DESCRIPTION OF THE GO-KART}

A go-kart is a kind of open-wheel auto. Go-karts come in all shapes and structures, from motor less models to powerful hustling machines. Numerous recreational karts can be controlled by four-stroke motors or electric engines, while hustling karts utilize a two-stroke or, occasionally, higher fueled four-stroke motors. A large portion of them are single seater yet some recreational models can oblige a traveler. In a few nations, go-karts can be authorized for use on open streets frequently alluded to as road tracks. To fabricate the complete go-kart, different parts like steering, braking, transmission systems, electrical and other innovative ideas are added to the go-kart.

\section{TECHNICAL SPECIFICATIONS OF GO-KART}

- Chassis Material

- Steering System

- Suspension System \& Go-Kart Dimensional Configuration

- Braking System

- Tire and Wheel

- Engine \& Transmission system

- Safety Materials

\section{DESIGN OF CHASSIS}

The Team members studied and analyzed the chassis designs of go-kart by considering what are the loads acting on the chassis frames and the parts attached to the chassis. Thereby, designed the outline of the rough chassis designs and analyzed them in software to get the Standard chassis body. 


\section{Rough Chassis Designs}

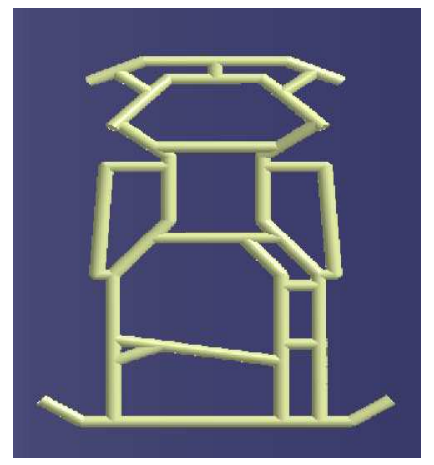

Figure 2: Old Chassis Design

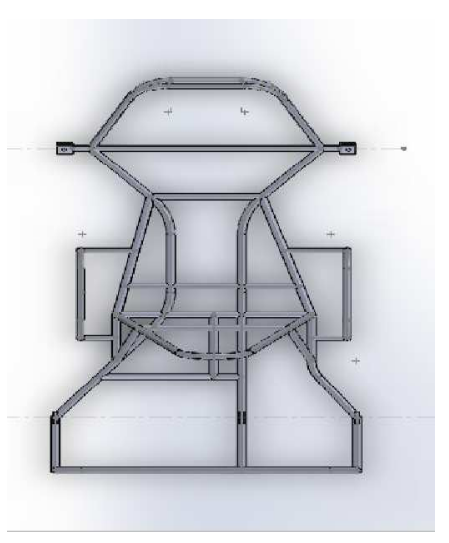

Figure 3: New Chassis Design

\section{Roll Hoop}

Roll hoop is placed between the engine compartment and the driver compartment. The Firewall sheets are attached to the roll hoop. The roll hoop should be placed at 2-3 inches from the seat, and engine should be placed at 1-2 inch from the roll hoop. According to it, the roll hoop should be adjusted on the chassis body with an inclination of 5-10 towards the engine. Height of the roll hoop should have a clearance of 3-5 inches from the top end of the driver helmet.

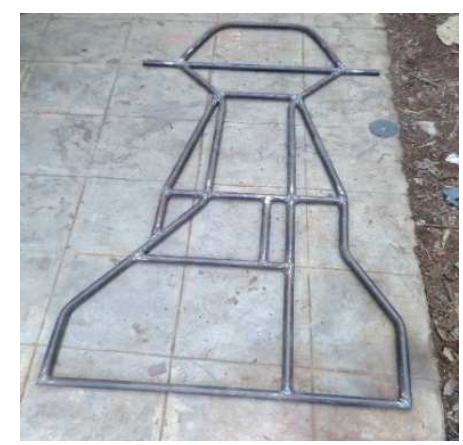

Figure 4: Roll Hoop

\section{Bumpers}

The bumpers should be placed at the front, rear and sides of the kart. The bumper material should be seamless pipes or fiber materials to cover the chassis body from all the angles. The bumpers should not allow the chassis body to deform during the accidents. The bumpers should take the max load during the accidents. 


\section{Driver's Leg Compartment}

The Driver leg compartment should be adjusted according to the driver comfortability of seating and his leg space for throttling and during application of brakes. Foot guard must be placed to protect the foot of the driver during accident or during collision with another kart.

\section{Driver's Seat Compartment}

Driver seat must be rigidly fixed to the chassis body. The driver seat must be positioned in an inclination according to the comfortability of the driver, so that the driver will not have back pain during riding of the go-kart. The driver seat must be bucket seat and there will be no seat belts present. Driver compartment should be arranged in a way that the driver should come out of the kart within 5 seconds during egress test.

\section{Engine Compartment}

The engine must be placed in the engine compartment in a way that it should be in diagonal to the driver seat arrangement to reduce the roll over effect of the vehicle. Engine compartment will have the engine, battery, transmission system, transmission shaft, sprocket and disc brake connected to the transmission shaft. Taking consideration of all the parts we should design the engine compartment.

\section{Suspension System}

There is no suspension system, because the ground clearance of the go-kart is max 2 inches.

\section{Wheel Base}

Wheel base of the go-kart is defined as the distance between the Centers of the front and rear axle tire. As per the rulebook of $3^{\text {rd }}$ IKR, go-kart should have wheelbase of min 44 inches.

\section{Track Width}

Track width of the go-kart vehicle should be min 0.75 of the wheelbase. It is the length between the centers of the either front tires or rear tires.

The go-kart should have a minimum ground clearance of about 2 inches. It is distance or gap between the lowest points of chassis to the ground.

\section{Weight of the Go-Kart}

The weight of the go-kart is the important aspect in designing chassis body. The go-kart should be a light vehicle to achieve the max speed in race track. The go-kart total weight should be less than $165 \mathrm{~kg}$ without the consideration of driver.

\section{Design of Go-Kart Vehicle and Analysis}

The primary goal is to design a vehicle that is practical and easy to use yet obtaining high performance. The team is separated into individual departments: Frame and Structural, Materials Testing, Safety, System Integration, Administration and Finance. Each design department is responsible for their respective aspect of the design, except for System Integration. 
The specific task of the system integration department is to ensure a cohesive design for which they necessitate checking for clearance issues, certain part requirements, and overall ensured everything would come together perfectly.

Design process after selecting various systems to be designed in software's - SOLIDWORKS 13.0, Ergonomics in CATIA and Analysis in ANSYS WORKBENCH 17.1. After obtaining results of analysis, if any constraints were found, we had gone for re-modeling, and the systems or components were retested and the constraints were rectified. This design process is based on various aspects in engineering and vice-versa liable on the obtainability of material, and all the parameters that are to be considered during selection of material. Our design mainly focuses on the strength, durability, safety, driver comfort, and pleasing look of the vehicle. To achieve the best design, we have divided the design team into groups as mentioned below.

\section{MODELING}

\section{Design Specifications}

Table 1: Vehicle Specifications

\begin{tabular}{|l|c|}
\hline \multicolumn{2}{|c|}{ Roll cage/chassis } \\
\hline Weight & $22 \mathrm{~kg}$ \\
\hline Material & AISI 4130 \\
\hline Outer diameter & $25.4 \mathrm{~mm}$ \\
\hline Thickness & $2 \mathrm{~mm}$ \\
\hline \multicolumn{2}{|c|}{ Vehicle Dimensions } \\
\hline Ground Clearance & $25.4 \mathrm{~mm}$ \\
\hline Wheelbase & $1168.39 \mathrm{~mm}$ \\
\hline Back Track width & $1117.6 \mathrm{~mm}$ \\
\hline Front track width & $1066.8 \mathrm{~mm}$ \\
\hline Overall Length & $1727.19 \mathrm{~mm}$ \\
\hline Overall Width & $1219.19 \mathrm{~mm}$ \\
\hline Height of RPS & $1016.0 \mathrm{~mm}$ \\
\hline
\end{tabular}

\section{Considerations}

Table 2: Vehicle Considerations

\begin{tabular}{|l|l|l|}
\hline Considerations & $\begin{array}{l}\text { Priority } \\
\text { Level }\end{array}$ & Validation \\
\hline Weight & 1 & $\begin{array}{l}\text { Light in weight kart gives best } \\
\text { output }\end{array}$ \\
\hline Durability & 1 & $\begin{array}{l}\text { Material shouldn't deform at } \\
\text { span of time or condition }\end{array}$ \\
\hline Cost & 4 & $\begin{array}{l}\text { Cost is the deciding factor as } \\
\text { kart should be within budget }\end{array}$ \\
\hline
\end{tabular}

\section{Software's Used}

Table 3: Software's Used

\begin{tabular}{|l|l|}
\hline PURPOSE & $\begin{array}{l}\text { SOFTWARE } \\
\text { EMPLOYED }\end{array}$ \\
\hline 3-D Model & Solid Works 13.0 \\
\hline Structural Analysis & ANSYS Workbench \\
\hline
\end{tabular}




\section{CAD Model of Chassis}

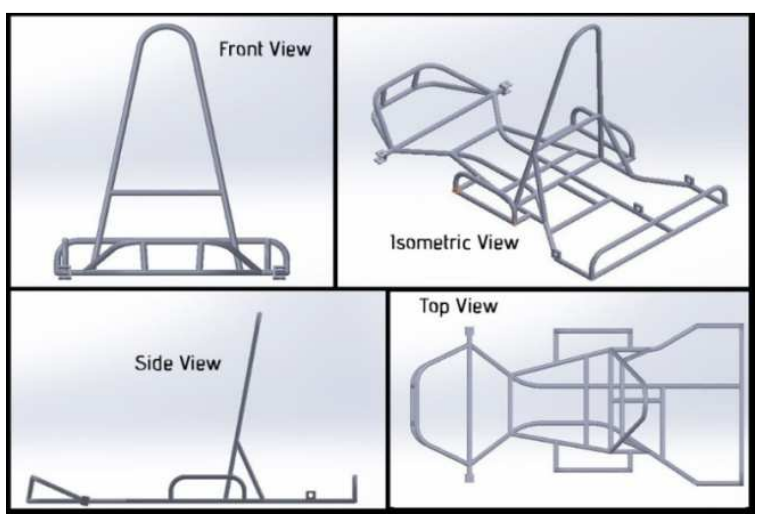

Figure 5: Views of Designed Model

\section{Load Analysis on the Material Chosen}

A load analysis is being carried out on the complete material selected, in order to verify the capabilities or properties are enough and sufficient for fabricating the Go-Kart. A long seamless pipe of length 19m was considered and the analysis was carried out with the pipe acting as cantileaver and simply supported.

Bending load on the chassis material, considering as cantileaver and simply supported seamless pipe. With various type of loads as point load and Udl acting on the seamless pipe.

\section{LOAD CONSIDERATIONS ON CANTILEAVER SEAMLESS PIPE}

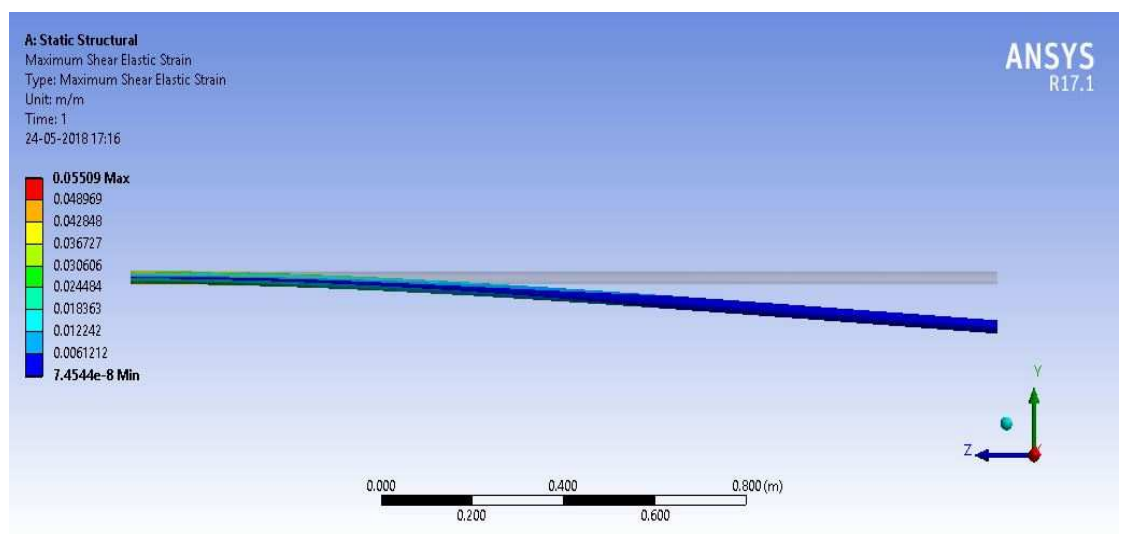

Figure 6: Maximum Shear Strain is 0.005509 while Applying Point Load on Pipe

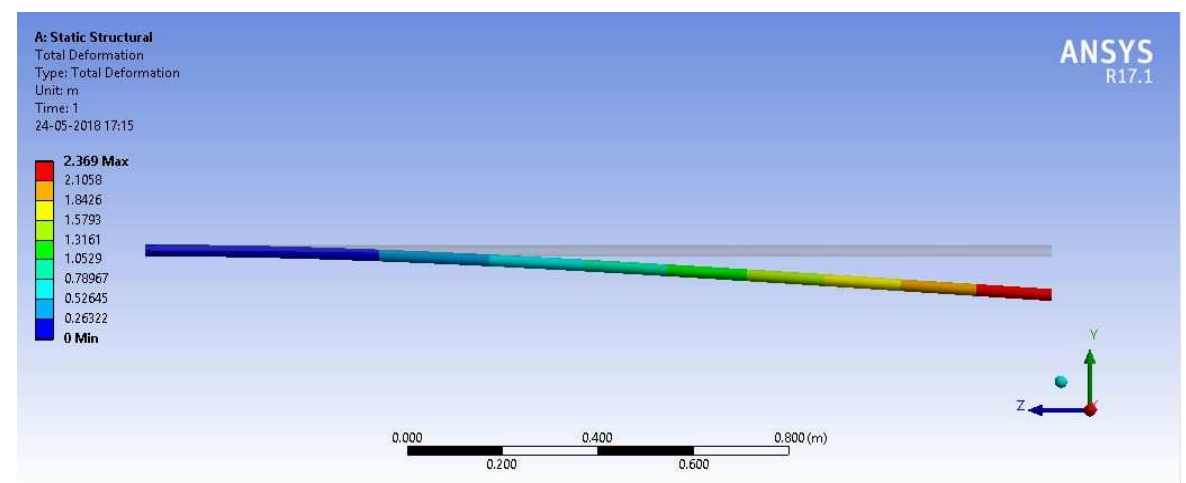

Figure 7: Total Deformation is 2.369m (Max.) while Applying Point Load on Pipe 


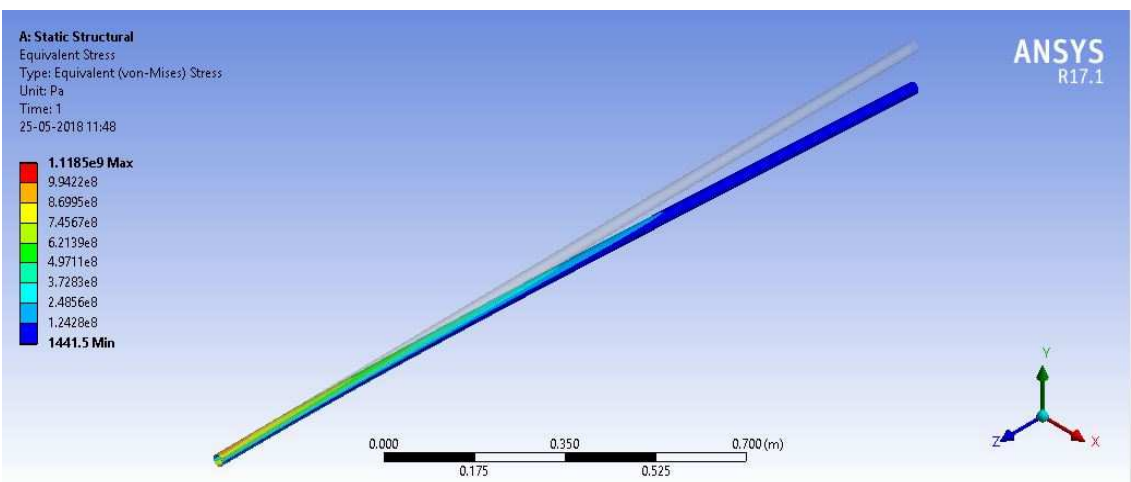

Figure 8: Equivalent Stress is 1.11e9Pa while Applying udl on Pipe

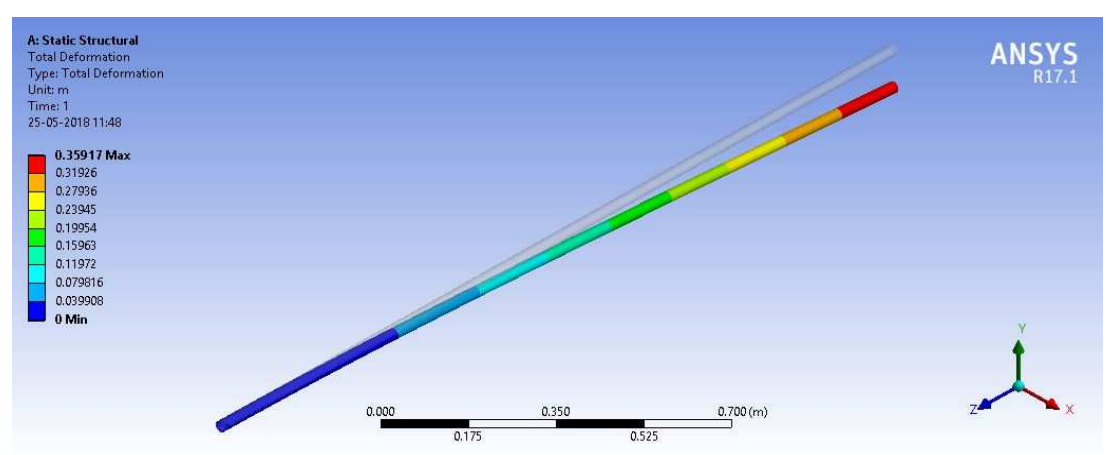

Figure 9: Total Deformation is 0.35m (Max.) while Applying udl on Pipe

\section{LOAD CONSIDERATIONS ON SIMPLY SUPPORTED SEAMLESS PIPE}

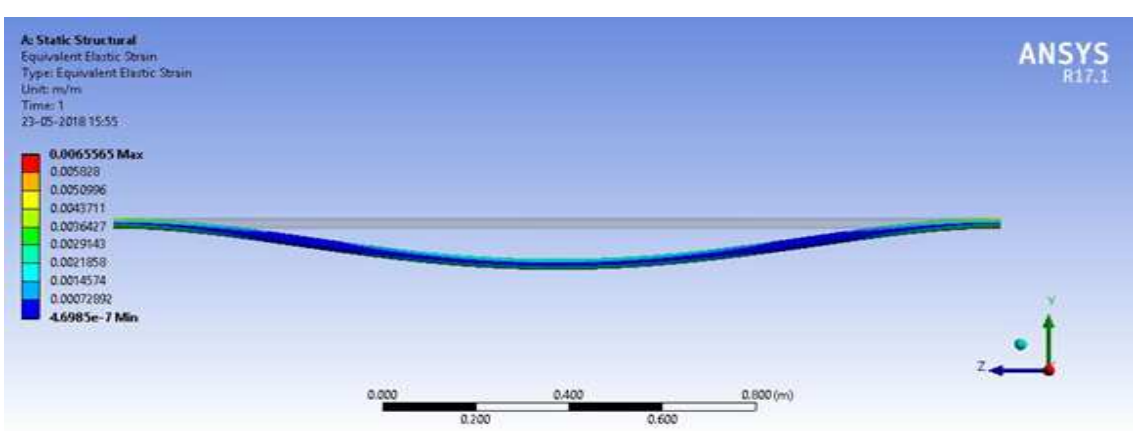

Figure 10: Equivalent Elastic Strain is 0.00655 while Applying Point Load on Pipe

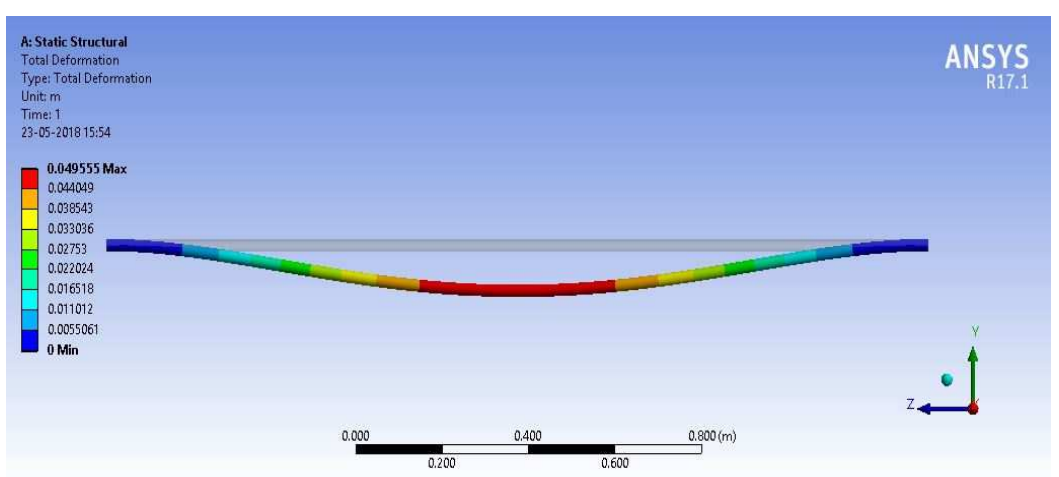

Figure 11: Total Deformation is $\mathbf{0 . 0 4 9 5 5 m}$ (Max.) when Subjected to Point Load 


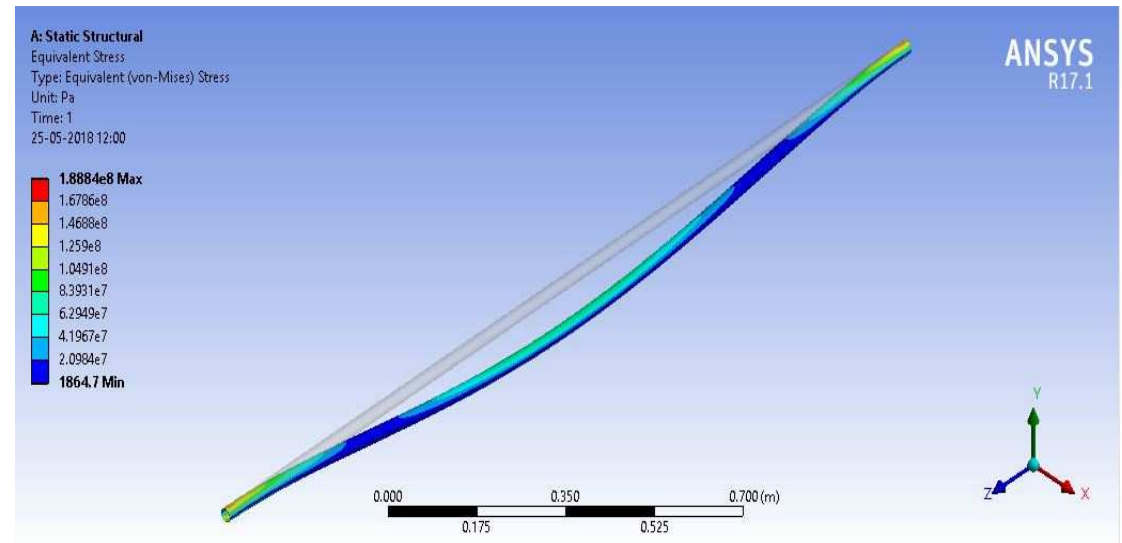

Figure 12: When Subjected to Point Load when Two Ends are Fixed

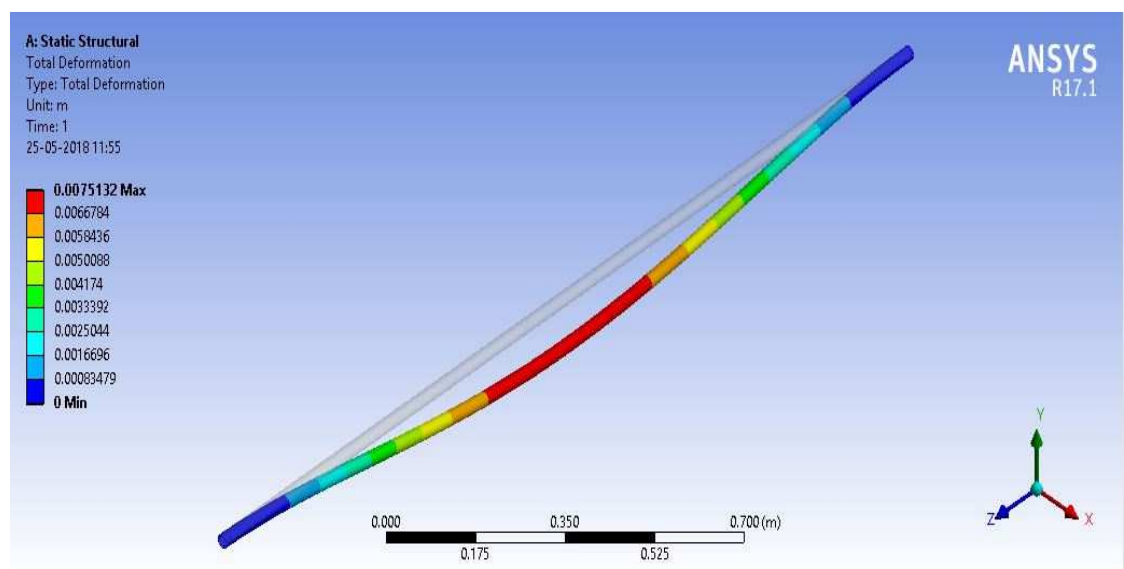

Figure 13: When Subjected to Udl Load when Two Ends are Fixed

\begin{tabular}{|c|c|}
\hline \multicolumn{2}{|l|}{ Scope } \\
\hline Scoping Method & Geometry Selection \\
\hline Geometry & 1 Face \\
\hline \multicolumn{2}{|l|}{ Definition } \\
\hline Type & Force \\
\hline Define By & Components \\
\hline Coordinate System & Global Coordinate System \\
\hline$\square \times$ Component & O. $\mathrm{N}$ (ramped) \\
\hline Y Component & $-3000 . N$ (ramped) \\
\hline Z Component & O. $\mathrm{N}$ (ramped) \\
\hline Suppressed & No \\
\hline
\end{tabular}

Figure 14: Considerations for the Load

\section{LINEAR BUCKLING ANALYSIS ON THE SEAMLESS PIPE}

A Linear buckling analysis is also called as the Eigen values-based buckling analysis. It calculates the bucking load magnitudes that cause buckling and associated buckling modes.

The below buckling analysis is done for the complete materials length i.e. $19 \mathrm{~m}$, as performing the analysis on small length material, it can be considered as the compressive load. So, to overcome this, buckling analysis is done over complete length of material. 


\section{THEORETICAL CALCULATIONS WITH RESPECT TO CRITICAL BUCKLING LOAD}

Both the materials AISI 4130 and AISI 1018 have the same yield strength values i.e., 210 Gpa. So, both the materials have the same Critical Buckling Load values.

$\mathrm{P}_{\mathrm{cr}}=\left(\Pi^{2} * \mathrm{EI}\right) /(\mathrm{KL})^{2}$

Where, $\mathrm{P}_{\mathrm{cr}}$ - Maximum or Critical Force

E - Modulus of Elasticity

I - Moment of Inertia of the cross section

L - length of column

$\mathrm{K}$ - one end fixed and other end free to move, $\mathrm{K}=2.0$

As the OD is $25.4 \mathrm{~mm}$ and ID is $23.4 \mathrm{~mm}$ the Moment of Inertia of the seamless pipe considered is

$I=\Pi\left(D^{4}-d^{4}\right) / 64$

$=\Pi(416231.425-250730.662) / 64$

$=8123.99 \mathrm{~mm}^{4}$

Critical Buckling Load,

$\mathrm{P}_{\mathrm{cr}}=\left(\Pi^{2} * \mathrm{EI}\right) /(\mathrm{KL})^{2}$

$=\left(\Pi^{2} * 210 * 10^{3} * 8123.99\right) /\left(2 * 19 * 10^{3}\right)^{2}$

$=51.96 \mathrm{~N}$

Over all Equivalent stress on the material $=\mathrm{P}_{\mathrm{cr}} / \mathrm{A}$

$=51.96 / 76.65$

$=0.67800 \mathrm{~N} / \mathrm{mm}^{2}$

\section{Material - AISI 4130}

The Eigen buckling Values obtained from the Load Multiplier in two modes are

- 7.6299

- 7.6307

Maximum Total Deformation with load multiplier (Linear): 7.6307 of AISI 4130 material is $1.3952 \mathrm{~mm}$ 


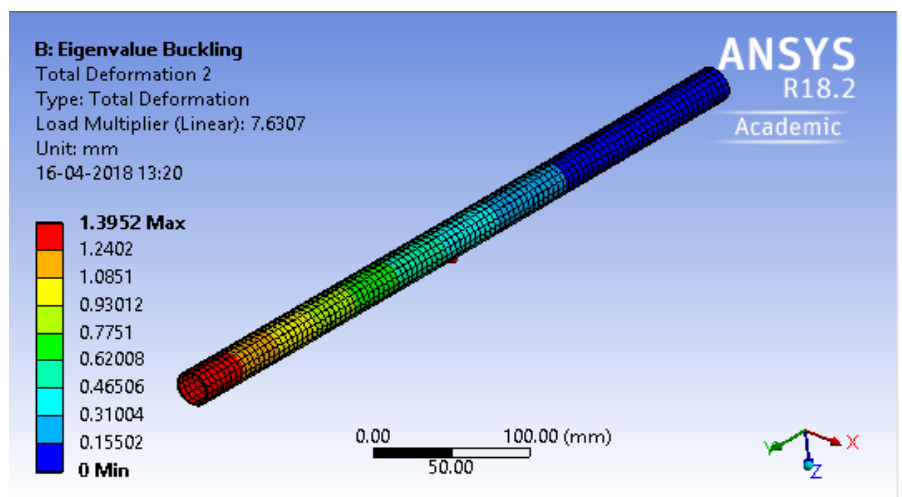

Figure 15

Maximum Total Deformation with load multiplier (Linear): 7.6299 of AISI 4130 material is $1.3952 \mathrm{~mm}$

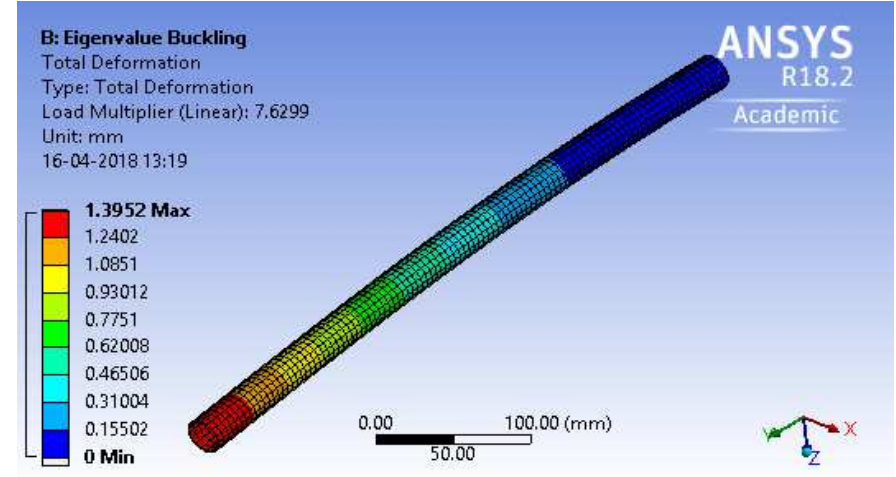

Figure 16

As the material withstands high buckling load and the bending moments, we considered the material, because the availability of the material is more in the market.

\section{THEORETICAL CALCULATIONS}

Mass of the Go-Kart $(\mathrm{M})=102 \mathrm{~kg}$.

\section{At Front}

Velocity $(\mathrm{V})=70 \mathrm{Km} / \mathrm{hr}$. $($ consider maximum $)=19.4 \mathrm{~m} / \mathrm{s}$

Force $(\mathrm{F})=\mathrm{P} * \Delta \mathrm{T}($ consider $\Delta \mathrm{T}=$ Time Difference $=1.1 \mathrm{sec})$

Momentum $(\mathrm{P})=\mathrm{M} * \mathrm{~V}=102 * 19.4=1978.8 \mathrm{Kg} \cdot \mathrm{m} / \mathrm{sec}$.

Force $=1978.8 * 1.1=\mathbf{2 1 7 6 . 6 8 N}$ 


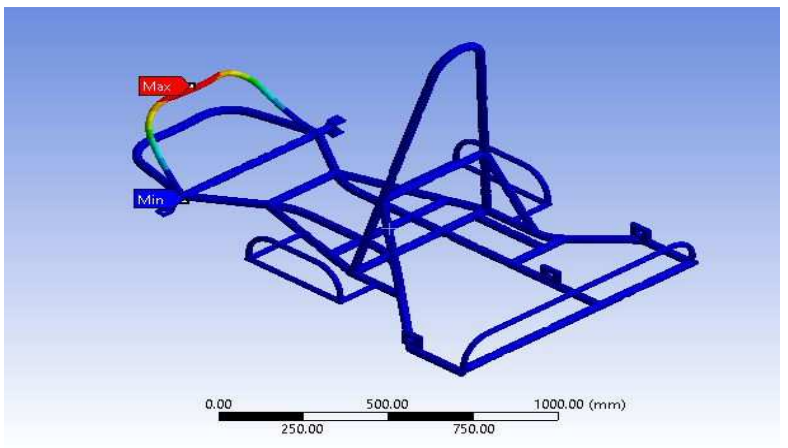

Figure 17: Deformed Chassis at Front

\section{At Side}

Velocity $(\mathrm{V})=40 \mathrm{Km} / \mathrm{hr} .($ consider maximum $)=11.11 \mathrm{~m} / \mathrm{s}$

Force $(\mathrm{F})=\mathrm{P} * \Delta \mathrm{T}($ consider $\Delta \mathrm{T}=$ Time Difference $=1.1 \mathrm{sec})$

Momentum $(\mathrm{P})=\mathrm{M} * \mathrm{~V}=102 * 11.11=1133.3 \mathrm{Kg} . \mathrm{m} / \mathrm{sec}$.

Force $=1133.3 * 1.1=\mathbf{1 2 4 6 . 6 3 N}$.

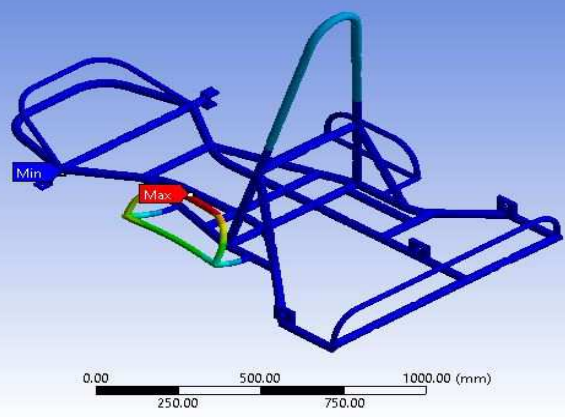

Figure 18: Deformed Chassis at Sides

\section{At Rear}

Velocity $(\mathrm{V})=55 \mathrm{Km} / \mathrm{hr}$. $($ consider maximum $)=15.27 \mathrm{~m} / \mathrm{s}$

Force $(\mathrm{F})=\mathrm{P} * \Delta \mathrm{T}($ consider $\Delta \mathrm{T}=$ Time Difference $=1.1 \mathrm{sec})$

Momentum $(\mathrm{P})=\mathrm{M} * \mathrm{~V}=102 * 15.27=1558.3 \mathrm{Kg} \cdot \mathrm{m} / \mathrm{sec}$.

Force $=1558.3 * 1.1=\mathbf{1 7 1 4 . 1 6 N}$.

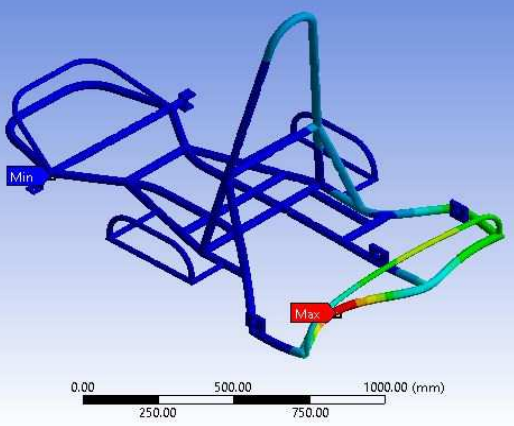

Figure 19: Deformed Chassis at Rear 


\section{ANALYSIS}

\section{Material: AISI 4130}

Table 4: Material Properties

\begin{tabular}{|c|c|}
\hline Ultimate tensile strength (Mpa) & 655 \\
\hline Ultimate yield strength (Mpa) & 415 \\
\hline Bulk modulus (Gpa) & 140 \\
\hline Shear modulus (Gpa & 80 \\
\hline Elastic modulus (Gpa) & 210 \\
\hline Poisson's ratio & 0.3 \\
\hline Brignell's Hardness & 197 \\
\hline Density (g/cc) & 7.85 \\
\hline
\end{tabular}

\section{Material: AISI 1018}

Table 5: Material Properties

\begin{tabular}{|c|c|}
\hline Ultimate Tensile Strength (Mpa) & 440 \\
\hline Ultimate Yield Strength (Mpa) & 370 \\
\hline Bulk Modulus (Gpa) & 140 \\
\hline Shear Modulus (Gpa) & 80.0 \\
\hline Elastic Modulus (Gpa) & 205 \\
\hline Poisson's Ratio & 0.29 \\
\hline Brinells Hardness & 126 \\
\hline Density (g/cc) & 7.87 \\
\hline
\end{tabular}

The Theoretical Values have been calculated to apply load on the either sides of the chassis frame. The loads applied on the Front, Side and Rear on both the material AISI 4130 \& AISI 1018. The Structural analysis results Equivalent Stress, Total Deformation and the Factor of Safety are as follows in the bellow mentioned table.

Table 6:Results of Load Acting on the Chassis

\begin{tabular}{|c|l|c|c|c|}
\hline S. No. & Load & $\begin{array}{c}\text { Equivalent } \\
\text { Stress }\end{array}$ & $\begin{array}{c}\text { Total } \\
\text { Deformation }\end{array}$ & $\begin{array}{c}\text { Factor of } \\
\text { Safety }\end{array}$ \\
\hline & \multicolumn{4}{|c|}{ AISI 4130 } \\
\hline 1 & Front & $106.67 \mathrm{Mpa}$ & $2.365 \mathrm{~mm}$ & 4.076 \\
\hline 2 & Rear & $56.69 \mathrm{Mpa}$ & $0.19877 \mathrm{~mm}$ & 7.6733 \\
\hline 3 & Side & $206.89 \mathrm{Mpa}$ & $1.668 \mathrm{~mm}$ & 2.1032 \\
\hline \multicolumn{5}{|c|}{ AISI 1018 } \\
\hline 4 & Front & $106.09 \mathrm{Mpa}$ & $2.0687 \mathrm{~mm}$ & 3.4826 \\
\hline 5 & Rear & $56.64 \mathrm{Mpa}$ & $1.8158 \mathrm{~mm}$ & 6.1215 \\
\hline 6 & Side & $210.84 \mathrm{Mpa}$ & $1.45 \mathrm{~mm}$ & 1.75 \\
\hline
\end{tabular}

By considering the factor of safety of the two materials, AISI 4130 is more suitable when compared to the AISI 1018 material. So, the selected chassis material to withstand heavy loads is AISI 4130. 


\section{RESULTS}

Front Impact at Different Speeds

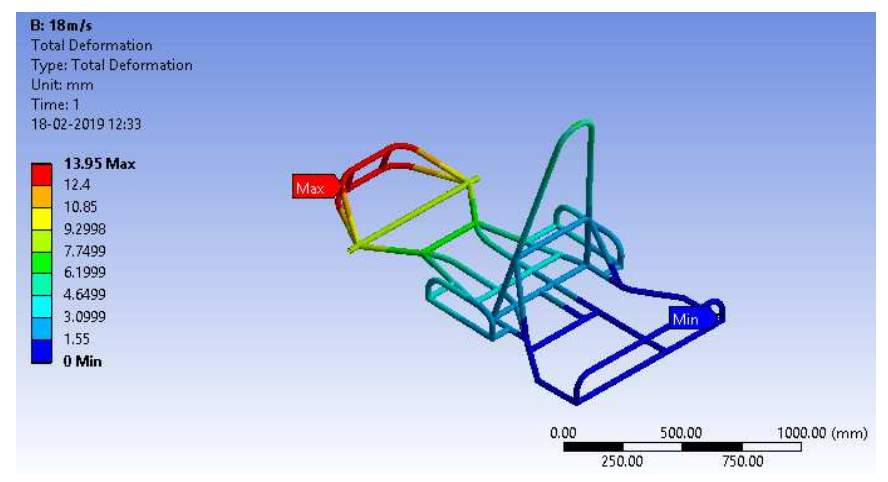

Figure 20: Deformation at a Speed of 18m/s

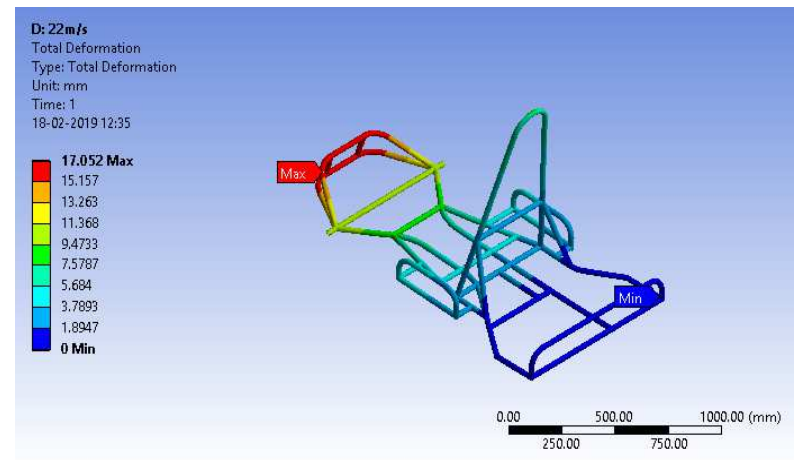

Figure 21: Deformation at a Speed of $22 \mathrm{~m} / \mathrm{s}$

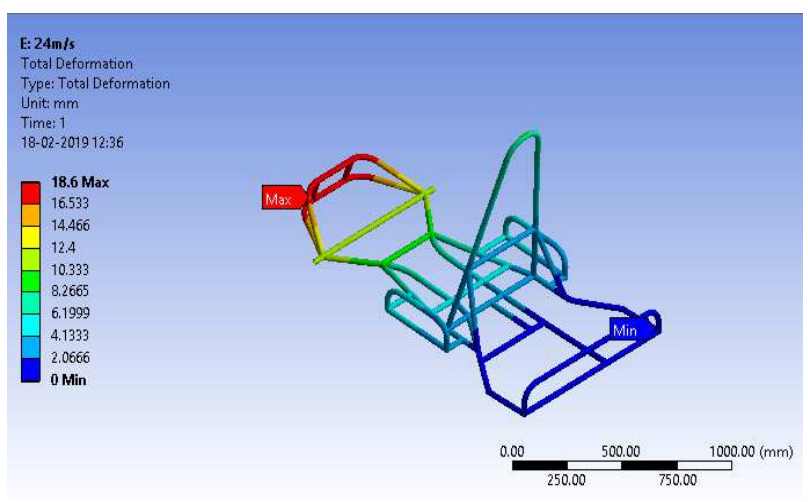

Figure 22: Deformation at a Speed of $24 \mathrm{~m} / \mathrm{s}$

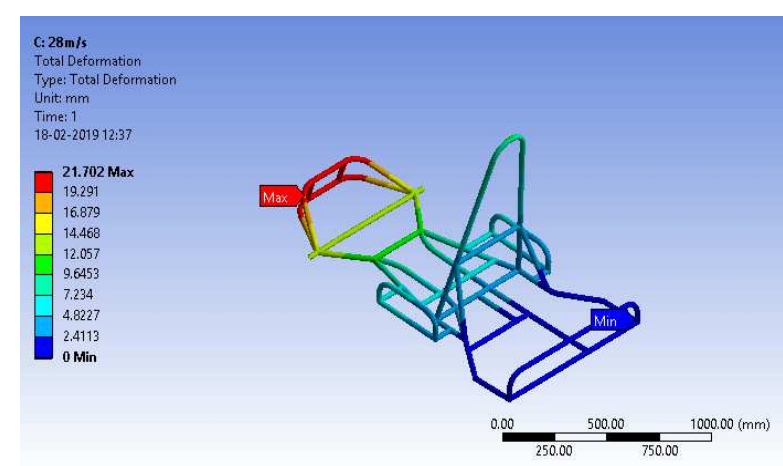

Figure 23: Deformation at a Speed of $28 \mathrm{~m} / \mathrm{s}$ 
Side Impacts at Different Speeds

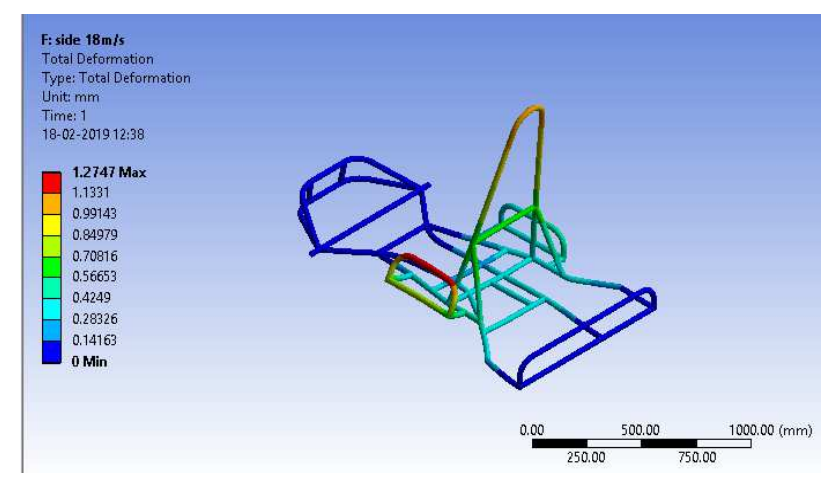

Figure 24: Deformation at a Speed of $18 \mathrm{~m} / \mathrm{s}$

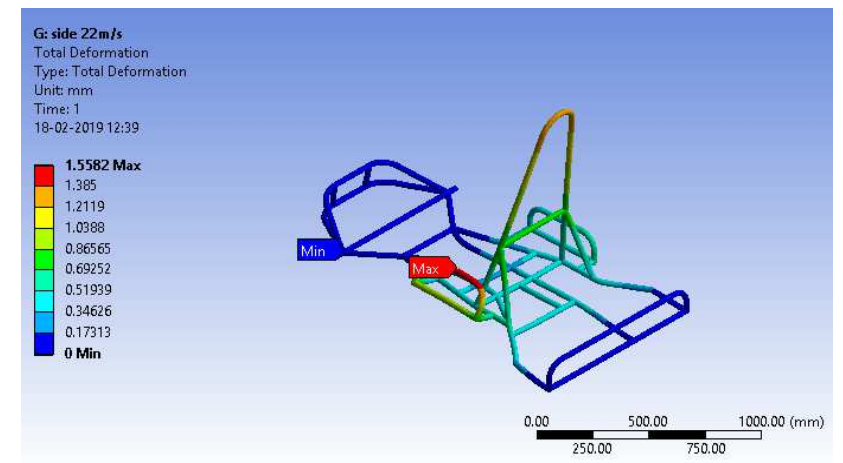

Figure 25: Deformation at a Speed of $22 \mathrm{~m} / \mathrm{s}$

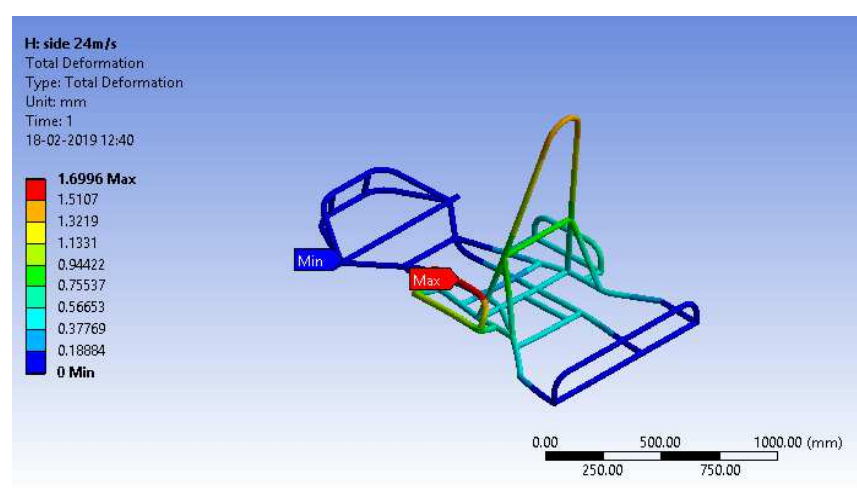

Figure 26: Deformation at a Speed of $24 \mathrm{~m} / \mathrm{s}$

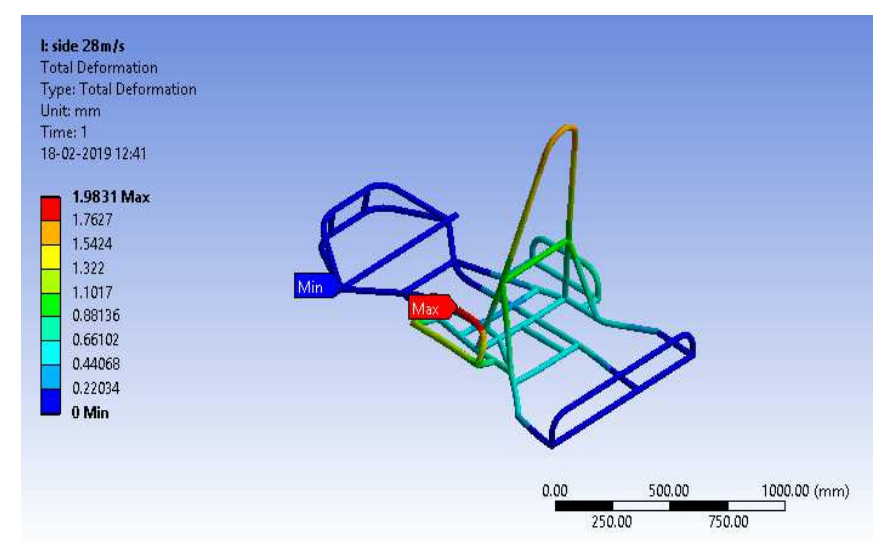

Figure 27: Deformation at a Speed of $28 \mathrm{~m} / \mathrm{s}$ 


\section{CONCLUSIONS}

From the above calculations, we have calculated AISI 4130 for two possible cases; first case chassis will be fixed in all conditions and second case partially fixed, assuming as a cantilever beam. And therefore, AISI 4130 is one of the best suitable materials for the fabrication of the Go-kart chassis as it has the high weight to strength ratio, which gives the better performance. The design of the chassis for the Go-kart helps in finding the strength and weakness of the design fabrication.

\section{REFERENCES}

1. http://www.ijrat.org/downloads/Convergence2017/Convergence-53.pdf

2. https://www.researchgate.net/publication/318760819_Static_Analysis_of_a_Go-Kart_Chassis

3. http://www.ijrat.org/downloads/Convergence2017/Convergence-53.pdf

4. https://www.ijedr.org/papers/IJEDR1802051.pdf

5. http://www.academia.edu/6943900/Static_analysis_of_GoKart_Chassis_frame_by_Analytical_and_Solid_Works_Simulation

6. https://www.scribd.com/document/363094656/Design-and-static-analysis-of-a-Go-Kart-Chassis-by-ANSYSsimulation 
